\title{
Volatility Spillover between Stock and Bond Returns: Evidence from ASEAN-5 Countries
}

\author{
Feny Yurastika $^{1}$, Buddi Wibowo ${ }^{2}$ \\ \{feny.yurastika@gmail.com ${ }^{1}$, buddi.wibowo@ui.ac.id ${ }^{2}$ \} \\ Department of Management, Faculty of Economics and Business, University of Indonesia, Jalan \\ Salemba Raya No. 4, Central Jakarta, 10430, Indonesia ${ }^{1,2}$
}

\begin{abstract}
This study investigated the volatility spillover between stock and government bond returns in ASEAN-5 countries, namely Indonesia, Malaysia, Philippine, Singapore, and Thailand using stock and government bond daily return data between 3 January 2006 and 28 February 2020. Estimation using BEKK-GARCH $(1,1,1)$ found that volatility spillover in ASEAN-5 countries are varied. There is no spillover volatility indication in Singapore and Malaysia. Meanwhile, unidirectional volatility spillover from the stock market to the government bond market was founded in Philippine and Thailand. Bi-directional volatility spillover, from the stock market to the bond market and from the bond market to the stock market occurred in Indonesia. The various result of ASEAN5 countries presumably caused by the different levels of financial and institutional depth among the countries. Countries with deep financial markets could absorb the shocks that occur so that it not spilled and affecting other markets.
\end{abstract}

Keywords: Volatility spillover, stock and bond returns, BEKK-GARCH.

\section{Introduction}

Increasing global financial market integration and interconnection provide great benefits to a country's economy by accelerating the development of the domestic financial market, increasing market efficiency, and opening foreign financing. However, the increase of global financial market integration and interconnection also raises the risk of vulnerability to external shocks in the domestic financial market. Economic openness makes financial markets interdependency increased. The global financial crisis has provided a case of how financial turmoil in one country can spread and impacted the entire world.

Many researchers have studied the interactions among financial assets and interactions among financial assets across countries, by trying to find the spillover behavior among the rate of return of financial assets such as stocks, bonds, and foreign exchange markets. Kang et al. [8] examined the pattern of spillover and connectedness among several financial assets, that is equity, commodities, bonds, and the United States equity market volatility index (VIX). They also studied the implications of the spillover and connectedness of those 
financial assets for portfolio diversification strategies. The study found that developed markets are net transmitter of volatility spillover while most of developing countries are net receivers of volatility spillover. Among the developed markets; the United States, France and Germany are countries that often transmit volatility, which is caused by the increased ownership of investors originating from these countries in developing countries' financial assets, as well as the abundance of liquidity caused by unconventional monetary policies by developed markets monetary authorities.

For developing countries, foreign portfolio flows are important funding sources for countries and corporations. Greater foreign investors' participation in developing market will broaden and diversify the investor base, reduce borrowing costs, and finally contribute to economic growth. However, dependence on foreign financing can also increase global economic uncertainty and increased portfolio flow volatility in developing countries IMF [6].

Over the past decade following the global financial crisis, foreign investor participation in developing countries including ASEAN-5 has increased significantly driven by abundant liquidity supported by accommodative policies in developed countries. Some developing countries such as Indonesia has become more dependent on the flow of foreign portfolios. The share of foreign investors' ownership, both in the stock market and the government bond market, have increased significantly which creates vulnerability, especially when the market conditions are depressed (Figures 1 and 2).

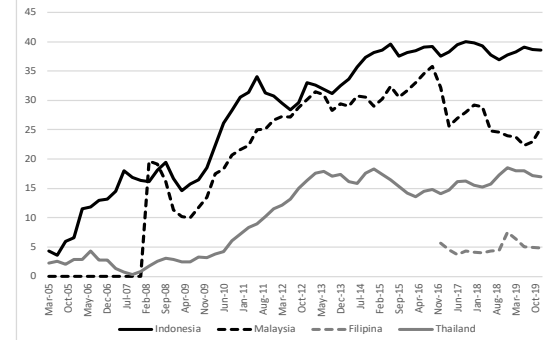

Fig. 1. Foreign Investors' Compositions in Stock Market

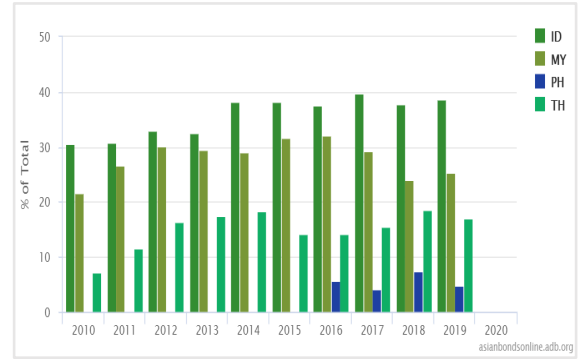

Fig. 2. Foreign Investors' Compositions in Local Currency Bond

Therefore, this study focuses on estimating the effects of spillover volatility between the stock and the bond returns for ASEAN-5 countries, namely Indonesia, Philippines, Malaysia, Singapore, and Thailand. This study focused on ASEAN-5 countries with several considerations. First, ASEAN is a new global force that should be taken into account in the world economy. With more than 600 million combined populations, ASEAN is the third-largest market in the world. If ASEAN is considered a single country, in 2050 ASEAN is 
projected to become the fourth largest economy in the world. Secondly, ASEAN-5 consists of one develop country and four developing countries that are integrated into global financial markets, becoming an investment alternative for foreign investors, reflected in the significant increase in foreign participation in the stock and bond markets in recent years. Third, the number of studies examining the behavior of volatility among financial assets, especially between the stock and bond returns in ASEAN-5 countries is relatively limited. Thus, this study will use the BEKK-GARCH methodology to capture the volatility spillover between the stock and bond markets in each of the ASEAN-5 countries. The analysis was conducted using daily stock index and government bond index data.

\section{Literature Review}

The important step in identifying investment objective is to set the risk tolerance. Every investor wants to get high returns with low risk. However, there is a trade-off between risk and return, the potential return rises with an increase in risk. Investment managers need to understand and measure risk along with risk tolerance for each investor. The concept of risk varies and differs for each individual and institution, making it difficult to define and measure. Risk tolerance is also difficult to set because it is personal and difficult to articulate. With these difficulties, investment managers must design, measure, and recommend risk tolerance for investors.

In finance, flight to quality refers to the investors' behaviour who shift their investment from risky assets to safer investment assets. Usually, investors shift their investment from stocks to bonds as bonds are considered as a relatively safer investment, especially during challenging economic times. Flight to quality also means a shift from risky assets to other assets that are considered more liquid and safer, such as government debt securities, money markets, and cash. One indication of the flight to quality is a drastic decrease in the government bonds yield. As demand in the government bonds increases, the prices will rise and yields will decrease.

Global Financial Stability Report, International Monetary Fund [6] reported that foreign portfolio flows act as an important funding source for the government and corporations in developing countries. Foreign investor portfolio investments can help expand the investor base for emerging market assets, lower funding costs, and ultimately contribute to higher economic growth. However, reliance on foreign financing also generates some risks. Therefore, investor needs to manage risks. Currently, emerging markets have 
become more dependent on foreign portfolio flows. Foreign investor participation in emerging markets has grown significantly since the global financial crisis, supported by accommodative policies in developed countries. In the equity market, foreign investor participation has traditionally been smaller than in the bond market, but in fact, foreign investors currently own a significant share of outstanding assets in several developing countries.

Changes in global conditions affect the prospect of foreign portfolio inflows. Positive global risk sentiment (risk-on) quickly increases foreign portfolio inflows to developing countries as foreign investors seek higher yield in these developing economies. But in the risk-off conditions (risk tolerance deteriorated), investors will withdrawal (capital outflow) her investment in countries especially countries with weaker fundamentals.

Moreover, IMF [6] found that foreign participation in local currency bond markets will increase bond yield volatility after reaching the specified threshold, while the deepening of domestic financial markets will help to reduce the bond yield volatility. When foreign investors bond holding exceeds 40 percent of the country's international reserves, it is found that the bond yield volatility increases by about 15 percent. By controlling the factors and threshold effects by foreign investors, the analysis found that the domestic financial market deepening reduces bond yield volatility significantly. Domestic financial market deepening helped developing country economies to reduce bond yield volatility by an average of 39 percent during 2004-2017.

Many studies have examined the impact of returns and volatility spillover between the stock and bond price in various countries using various methodologies. Before, many researchers studied the spillover effect using the causality method developed by Granger [9] and the Vector Autoregressive (VAR) method developed by Sims [9]. In a recent study, the multivariate GARCH model was frequently used, because it can simultaneously capture the spillover volatility of more than one financial asset.

Some research, such as a study conducted by Sun and Zhang [10], focuses on return and volatility spillover between the stock market in developed and developing countries. Sun and Zhang studied price and volatility spillover between the U.S. and China, and between the U.S and Hong Kong stock market during the subprime crisis using the univariate and multivariate GARCH models. The study found that there were price and volatility spillover from the U.S. stock market to the Chinese and Hong Kong stock markets.

Kang et al. [7] studied the spillover between CDS markets in nine countries namely Brazil, China, Indonesia, Korea, Malaysia, Philippines, Russia, South Africa, and Thailand using the DECO-GARCH multivariate model. The study used weekly emerging sovereign CDS data for the period from 7 January 2005 
to 15 July 2016. The results showed that the volatility spillover effect has increased since the last global financial crisis. This finding supports the contagion effect that occurs during the turmoil market.

Alkan and Çiçek [2] seek to capture the volatility spillover between financial markets in the Turkish economy, that are the foreign exchange, stock, and bond markets and then investigate the effects of global markets on the Turkish financial market. Using the BEKK-GARCH diagonal method on daily data between 2006 and 2018, it was found that there was a strong mean spillover from global markets to the domestic stock and bond markets, from the stock and foreign exchange markets to the bond market, and from the foreign exchange market to the stock market. For volatility spillovers, the results also support a strong spillover between each market. This finding implies that the Turkish economy is well integrated into global markets and that fluctuations in volatility in global or domestic markets will spread to other domestic markets. The BEKK-GARCH diagonal method used in this study is the development and a restricted model of the BEKK-GARCH method that reduces the number of parameters needed in the BEKK-GARCH method. However, the BEKKGARCH diagonal method limits cross-dynamic analysis while the BEKKGARCH method is preferred by researchers because the spillover effect of volatility can be directly known from the parameter coefficients estimated in the model.

Dean et al. [3] studied the volatility spillover effect between the stock and government bond markets in Australia using the BEKK-GARCH asymmetry method. This study believes that the spillover effect between the stock and bond markets arises when the transmission of information between these markets is incomplete. The study found that the spillover dynamics of the stock and bond markets are asymmetrical. For return volatility, bad news from the bond market has a spillover effect on the lower stock market returns, but the reverse is not true. Spillover effects occur from the bond market to the stock market, but not vice versa.

A number of studies have examined the relationship between returns and volatility in the stock market between countries. On the other hand, only a few researchers trying to see the spillover effect between the stock and bond markets within the country, especially developing countries. We know that the dynamics of bond prices have implications for the determination of stock prices for market participants who intend to strengthen the capital structure through the capital market and the decline in share prices caused by the increase in market uncertainty can increase the discount rate for all assets including bonds.

Furthermore, considering that the stock and bond markets are the main financial assets and take for more than half of the financial assets allocated 
worldwide, this study focuses on looking at volatility spillover between the stock and bond markets in ASEAN-5 countries, namely Indonesia, Malaysia, Philippines, Singapore, and Thailand using the multivariate GARCH method, namely BEKK-GARCH.

\section{Methodology}

The data used to analyze the volatility spillover and interaction between stock and bond market are daily quantitative data from the closing stock price index (stock index) and the closing government bonds price index (bond index) in ASEAN-5 countries (Indonesia, Malaysia, Philippines, Singapore, and Thailand). The period investigated extends from 3rd January 2006 to 28th February 2020. Excluding days when either one or both of the markets were closed. Data will be analyzed for each country, by analysing the condition of the stock market and the government bond market (bond market) in each country, then compare the result between countries. The stock index data used for Indonesia, Philippines, Malaysia, Singapore, and Thailand are LQ45, PSEi, KLCI, STI, and SET 50, respectively. Meanwhile, the government bond indexes used are the government bond indexes data managed by the NYSE Intercontinental Exchange (ICE).

This research will examine the behavior of return volatility of each stock and government bond index in each ASEAN-5 country (Indonesia, Malaysia, Philippines, Singapore, and Thailand). Risk or volatility behavior measured using the Generalized Autoregressive Conditional Heteroscesdaticity $(\mathrm{GARCH})$ volatility estimator model. Furthermore, spillover and interaction between the stock and bond market in each country will be observed using the multivariate GARCH model, which was developed by Engle and Kroner [4], called BEKK-GARCH. The BEKK-GARCH model used in the analysis is a full model in which spillover behavior can be seen directly from the conditional variance parameters generated in the model. The methodology used in this study are as follows:

1. Calculating Return

The data used in this study are daily stock and government bond index. Index return is relative return or log-return of stock and government bond index. If $P_{t}$ is the time series of a financial asset, then $r_{t}$ or log-return for day- $t$ can be calculated as: 


$$
r_{t}=\log P_{t}-\log P_{t-1}=\log \left(\frac{P_{t}}{P_{t-1}}\right)=\log \left(1+\frac{P_{t}-P_{t-1}}{P_{t-1}}\right)
$$

Before using GARCH or BEKK-GARCH method, data returns must be tested for the classical econometric assumptions, that are; stationary test using the Augmented Dickey-Fuller test, normality test using the JarqueBera test, and volatility or variance homogeneity test using the white heteroscedasticity test.

2. Stock and Government Bond Volatility Model

The GARCH model is an extension of the ARCH model. GARCH model makes conditional variance as ARMA process with error formulated as follow:

$$
\varepsilon_{t}=v_{t} \sqrt{h_{t}}
$$

with the means of $v_{t}$ is zero $\left(E\left(v_{t}\right)=0\right)$; variance of $v_{t}$ is one $\left(\sigma_{v}^{2}=1\right)$; and $v_{t}$ follow independent white noise process, no correlation between its value at different times $\left(\varepsilon_{t-1}\right)$, so that conditional mean and unconditional mean of $\varepsilon_{t}$ equal zero. Meanwhile, $h_{t}$ is a scale factor. The general form of $h_{t}$ is expressed as:

$$
h_{t}=\alpha_{0}+\sum_{i=1}^{q} \propto \varepsilon_{t-1}^{2}+\sum_{i=1}^{p} \beta h_{t-1} .
$$

If $q$ is the GARCH parameter and $p$ is the ARCH parameter, while $\sigma^{2}$ is the conditional variance and $\gamma$ is the regression parameter then $\operatorname{GARCH}(p, q)$ function consist of two elements:

a. Conditional mean or mean equation:

$$
\mathrm{y}_{\mathrm{t}=} \mathrm{x}_{\mathrm{t}} \gamma+\varepsilon_{\mathrm{t}}
$$

b. Conditional variance:

$$
\sigma_{\mathrm{t}}^{2}=\omega+\sum_{\mathrm{i}=1}^{\mathrm{q}} \alpha_{\mathrm{i}} \varepsilon_{\mathrm{i}-1}^{2}+\sum_{\mathrm{j}=1}^{\mathrm{p}} \beta_{\mathrm{j}} \sigma_{\mathrm{t}-\mathrm{j}}^{2}
$$

Alexander [1] explains that $\alpha$ and $\beta$ parameters show the short-run dynamics of the time series volatility. The greater the value of $\beta$, the variance tends to persistent meaning that in the time of shocks, it will take a longer time for the conditional variance to back to its normal condition. On the other hand, the greater the value of $\alpha$ means that volatility effect mostly by condition of market movement. 
3. Stock and Government Bond Volatility Spillover Model

The BEKK model reduces the number of independent parameters and guarantees a positive definite covariance matrix. The positive definite conditional variance is obtained from the formation of a model structure that has a positive definite property by doing a quadratic equation, that is:

$$
H_{t}=\Omega^{\prime} \Omega+\sum_{j=1}^{q} \sum_{k=1}^{K} A_{k j}^{\prime} \varepsilon_{t-j} \varepsilon_{t-j}^{\prime} A_{k j}+\sum_{i=1}^{p} \sum_{k=1}^{K} B_{k i}^{\prime} H_{t-i} B_{k i} .
$$

The simple BEKK $(1,1,1)$ model can be expressed as:

$$
H_{t}=\Omega^{\prime} \Omega+A^{\prime} \varepsilon_{t-1} \varepsilon_{t-1}^{\prime} A+B^{\prime} H_{t-1} B
$$

$A, B$, and $\Omega$ are parameter matrices $n \times n$ with $\Omega$ is a lower triangular matrix. The constant is set as the multiply of two lower triangular matrices to ensure that $H_{t}$ is positive definite. In the BEKK model, we can perform casualty in variance analysis because the conditional variance depends on the lag of other variables. The BEKK model is very flexible but, on the other hand, still need many free parameters, especially for more than four elements model.

\section{Analysis and Discussion}

\subsection{Descriptive Analysis of the Stock and Government Bond Return}

Figure 3 shows that, in all ASEAN-5 countries, stock returns have higher volatility than the government bond return. The highest volatility captured from data happened during the global financial crisis (GFC) 2008. This figure also describe volatility clustering, when a certain period showed a high return volatility clusters and other periods of low return volatility clusters.
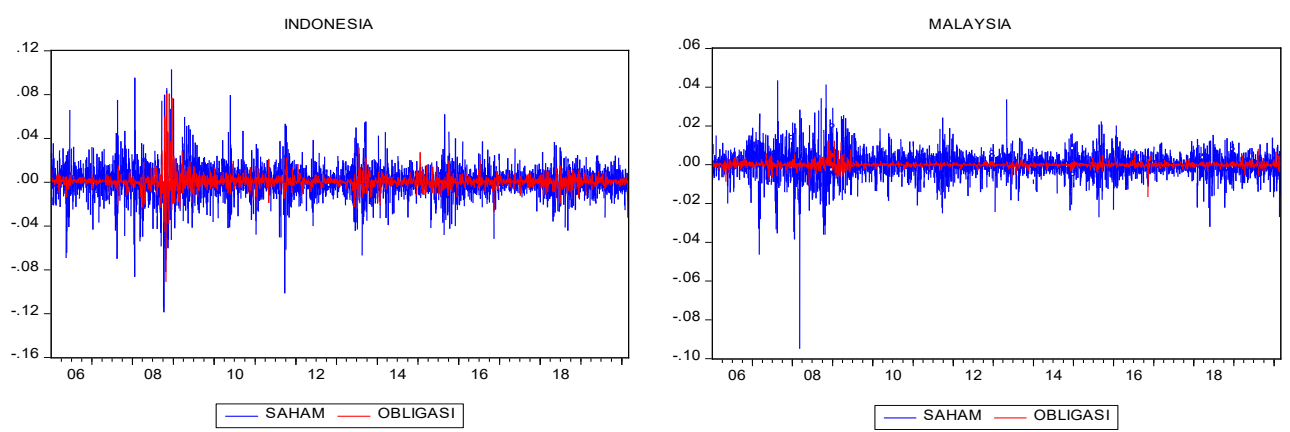


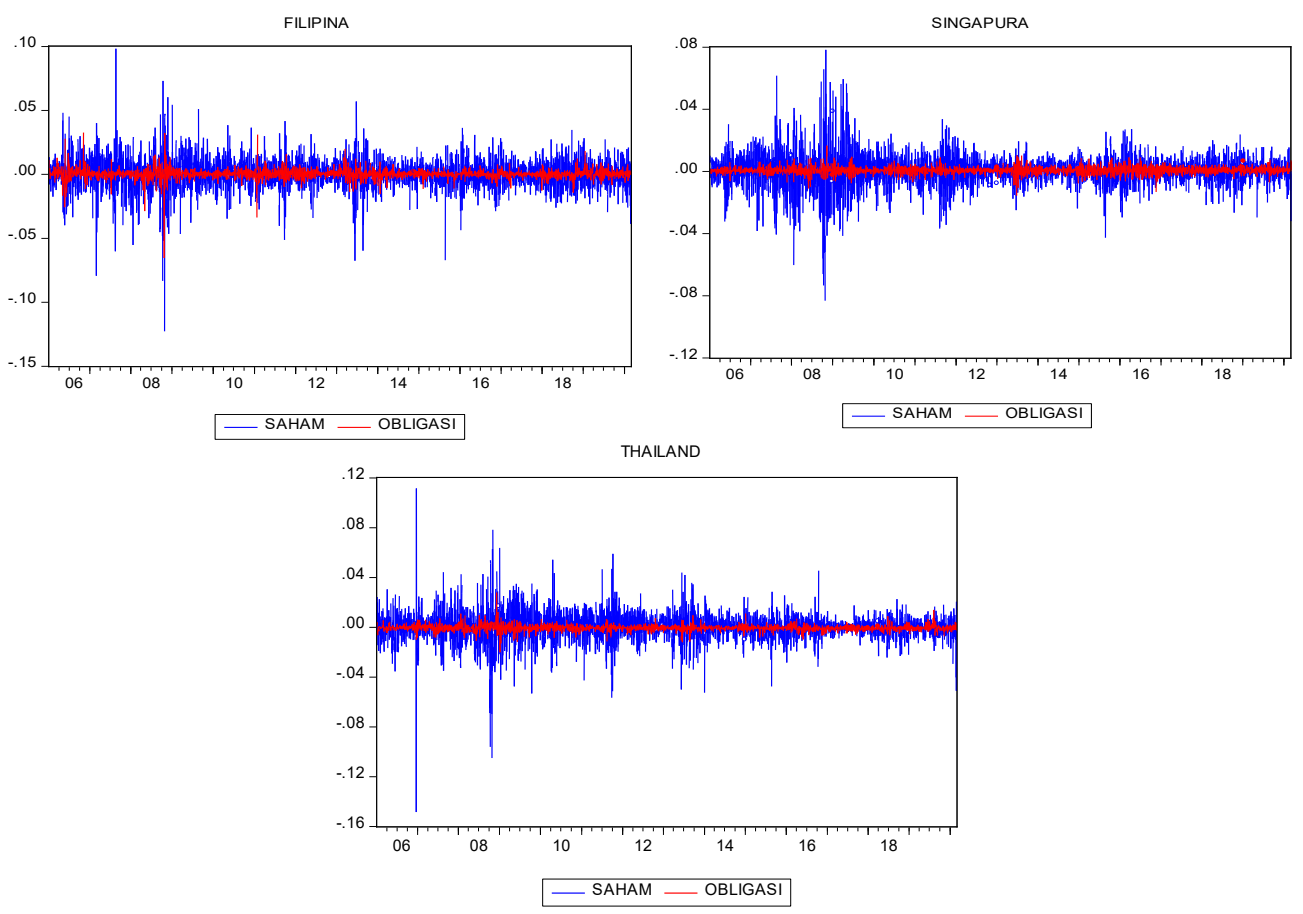

Fig. 3. Stock and Government Bond Returns Plot of ASEAN-5 Countries

Tables 1 and 2 show descriptive statistics of daily returns of stock and government bond returns for each of the countries in the analysis. Stock and government bonds price index used in the analysis are daily data so the mean of returns on the stocks and government bonds tends to be close to zero.

In investments, the rate of return is in line with the risk taken. The higher the risk taken, the higher the expected return, and vice versa. Table 1 shows that the Indonesian stock market generates the highest return compared to other countries. This highest return is in line with the risk level which is the highest among other countries. In contrast, Malaysia stock market gave the second lowest return and the lowest risk.

For the data distribution, stock return in all ASEAN-5 countries shows a negative skewness, which means that the distribution of returns is concentrated on the right side of the curve with an elongated tail on the left. Negative skewness indicates that investors will experience frequent small profits and rare large losses. 
Table 1. Descriptive Statistic of Stock Return

\begin{tabular}{ccccc}
\hline Countries & $\begin{array}{c}\text { Means } \\
\text { (in percentage) }\end{array}$ & $\begin{array}{c}\text { Std. Deviation } \\
\text { (in percentage) }\end{array}$ & Skewness & Kurtosis \\
\hline Indonesia & 0,0445 & 1,4815 & $-0,2981$ & 10,7000 \\
Malaysia & 0,0159 & 0,6945 & $-0,9740$ & 16,6380 \\
Philippines & 0,0391 & 1,2054 & $-0,5129$ & 10,9161 \\
Singapore & 0,0131 & 1,0549 & $-0,0673$ & 10,1968 \\
Thailand & 0,0238 & 1,1594 & $-0,7737$ & 19,2924 \\
\hline
\end{tabular}

Table 2 shows that Indonesia government bond market also gives the highest return and risk compared to other countries. On the other hand, Singapore government bond generates the lowest returns with moderate levels of risk. The skewness of the government bond returns in ASEAN-5 countries tends to vary. Indonesia and Thailand government bonds have a right-skewed distribution of return (positive skewness), while Singapore, Malaysia, and Philippines government bond returns have negative skewness. If investing in the government bond markets with negative skewness, investors will more often get a small positive return and rare large negative return. Meanwhile, if investing in Indonesia and Thailand government bonds with positive skewness, investors will experience frequent small losses and rare large gains. A large positive kurtosis indicates that the government bond return has more values close to the means or called leptokurtic.

Table 2. Descriptive Statistic of Government Bond Return

\begin{tabular}{ccccc}
\hline Countries & $\begin{array}{c}\text { Means } \\
\text { (in percentage) }\end{array}$ & $\begin{array}{c}\text { Std. Deviation } \\
\text { (in percentage) }\end{array}$ & Skewness & Kurtosis \\
\hline Indonesia & 0,0438 & 0,5868 & 1,0345 & 57,3031 \\
Malaysia & 0,0175 & 0,1232 & $-0,3245$ & 28,6044 \\
Philippines & 0,0320 & 0,3517 & $-1,6573$ & 47,4669 \\
Singapore & 0,0126 & 0,2163 & $-0,1750$ & 7,4039 \\
Thailand & 0,0231 & 0,2211 & 0,3764 & 15,8016 \\
\hline
\end{tabular}

From table 1 and table 2 we can see that the risk of investing in the stock market is higher than the government bond market. The higher risk will be rewarded with a higher return. The investment manager will manage their portfolios by allocating their investment in these two markets. If an investment manager wants to take a higher risk, then he will invest more in the stock market. Meanwhile, if an investment manager wants to avoid risk, he will invest more in the government bond market. 
If an investment manager decides to construct a portfolio consisting of stocks and government bonds in a particular country, he needs to consider that the risk level of both markets differs. The risk measured by standard deviation indicates that the risk in the stock market is two to six times higher than the risk in the government bond market in each country. Stock price fluctuations are much more volatile compared to the government bond market.

From the risk-return trade-off view, investing in Indonesia and Philippine stock markets is attractive because it offered high returns and moderate risks. As for the government bond market, an investor can choose to invest in either Malaysia or Thailand's government bond market.

Table 3. Correlation between Stocks and Government Bond Return

\begin{tabular}{cc}
\hline Countries & $\begin{array}{c}\text { Correlation between Stock and } \\
\text { Government Bond Return }\end{array}$ \\
\hline Indonesia & 0,29359 \\
Malaysia & 0,04298 \\
Philippines & 0,17896 \\
Singapore & $-0,15759$ \\
Thailand & 0,01083 \\
\hline
\end{tabular}

Correlation between stock and government bonds return shows, albeit relatively weak, tend to move in the same direction in all ASEAN-5 countries except Singapore. Stock and government bonds return in developing countries tend to move in the same direction presumbaly due to domination of foreign investors. Thus, if there is a risk-off situation in the global market, foreign investors will liquidate their investment in developing countries, both in the stock market and government bond markets, causing the two markets to be depressed. Likewise, in the event of a risk-on condition in global markets, foreign investors will return to invest in developing countries, both the stock and government bond, causing a rally in both markets. This finding is in line with the Global Financial Stability Report published by the International Monetary Fund [6] which states that the increasing role of foreign investors in developing countries has increased the risk of vulnerability, especially in a condition of market turmoil.

Tauchen and Pitts [11] also explain that financial market liberalization will reduce market volatility should it succeeds in attracting new investors, especially investors from developed markets with investment decisions and strategies based on rational investment analysis and fundamental assessment. However, financial market liberalization also attracted short-term speculators 
and investors, this will increase the vulnerability of a country to turmoil that happened in other parts of the world, such as increasing global stock market volatility, asset price bubbles, and disrupting financial stability.

Meanwhile, correlation or interaction between stock and government bonds return in Singapore moves in the opposite direction, supported by developed financial markets compare to other countries. The theory of flight-to-quality or flight-to-safety implies that the stock market and government bond market will have a negative correlation. If the market experiences high uncertainty, investors will shift their investment from risky assets (stocks) to safer assets (bonds). Conversely, if the market is experiencing an uptrend market (bullish), investors will switch from safe assets (bonds) to riskier assets (stocks).

Figures 1 and 2 peviously describe that role of foreign investors is dominant in both the stock and government bond market. Economic conditions in developing countries such as Indonesia, Malaysia, and Thailand have grown well in the last decade has attracted foreign investors to invest. The foreign composition in stock market trading in Indonesia and Thailand has increased over time. The share of foreign investors in Indonesia stock and government bond markets is nearly $40 \%$. This explains the condition that the stock and government bond markets in Indonesia tend to move in the same direction. Meanwhile, the share of foreign investors in Malaysia both in the stock market and government bonds is less than 30\%, and tended to decline since 2016 .

Using correlation to see the interaction between two variables, in this case, the stocks and government bond return has limitations. The correlation only looks at the relationship between two variables. If the two variables are said to have correlation then if stock returns move, government bond returns will also move, either the movement is unidirectional (positive correlation) or the movement is in different directions (negative correlation). But correlation cannot tell which variable moves first and know the cause and effect of the interaction. In addition, correlation can only assess linear interaction. It cannot use to determine the non-linear interaction between stock returns and government bonds returns. So in the next part of the analysis, we will use a dynamic estimation method, namely the multivariate GARCH method or more specifically BEKK-GARCH.

\subsection{Volatility Analysis of the Stock and Government Bond Return}

Table 4 shows that all ARCH $(\alpha)$ and GARCH $(\beta)$ estimation parameters for the stock return volatility in the GARCH model $(1,1)$ are statistically significant at the $1 \%$ level for all ASEAN-5 countries. ARCH parameter $(\alpha)$ that 
has a positive value indicates that, on average, the current volatility $(\mathrm{t})$ depends on the size of the previous volatility. The great volatility in this period $(\mathrm{t})$ will increase the volatility in the next period $(t+1, t+2$, and so on). While the GARCH parameter $(\beta)$ that has a positive value indicates that, on average, the current volatility $(\mathrm{t})$ depends on the volatility of some of the previous period. By knowing the pattern of return volatility, investors are expected to be able to control and reduce portfolio risk, especially when making investment allocations in the stock market across ASEAN-5 countries.

Table 4. Stock Return Volatility Model Output

\begin{tabular}{ccccc}
\hline Countries & $\omega$ & $\alpha$ & $\beta$ & $\alpha+\beta$ \\
\hline \multirow{2}{*}{ Indonesia } & 0,0000 & 0,0944 & 0,8902 & 0,9847 \\
& $(0,0000)$ & $(0,0062)$ & $(0,0063)$ & \\
Malaysia & 0,0000 & 0,1013 & 0,8850 & 0,9863 \\
& $(0,0000)$ & $(0,0056)$ & $(0,0067)$ & \\
Philippines & 0,0000 & 0,1089 & 0,8673 & 0,9762 \\
& $(0,0000)$ & $(0,0071)$ & $(0,0072)$ & \\
Singapore & 0,0000 & 0,0801 & 0,9125 & 0,9926 \\
& $(0,0000)$ & $(0,0063)$ & $(0,0067)$ & \\
Thailand & 0,0000 & 0,1187 & 0,8712 & 0,9899 \\
& $(0,0000)$ & $(0,0088)$ & $(0,0078)$ & \\
\hline
\end{tabular}

Notes:

- $\operatorname{GARCH}(1,1)$ model.

- All parameters significant at 1\% level.

- Standard error in paraphrase.

It can be concluded that the ARCH parameter $(\alpha)$ shows the short-term volatility effect while the GARCH $(\beta)$ parameter shows the long-term volatility effect. Table 4 shows that the volatility of stock returns in all ASEAN-5 countries is influenced by the volatility of some of the previous period (GARCH effect).

Table 5 shows the GARCH $(1,1)$ return volatility parameter on the government bond market in ASEAN-5 countries. Volatility parameter $\alpha$ and $\beta$ show that the return volatility of Indonesia, Malaysia, and Philippines government bond is higher than the return volatility in their stock market. If we look further on the ARCH parameter that shows short-term volatility effect, the Indonesia and Malaysia government bond short-term volatility effect is higher than its stock short-term volatility effect. This means that the great volatility in 
this period $(\mathrm{t})$ will have a greater impact on the next period $(\mathrm{t}+1)$ for Indonesia and Malaysia government bond market. Meanwhile, the volatility of the government bond market in Singapore and Thailand is relatively lower than the return volatility on its stock market.

In the variance equation model, the total volatility of the stock and government bonds can be calculated as the sum of the ARCH $(\alpha)$ and GARCH $(\beta)$ coefficients. The total volatility can be categorised into low, high, and extremely high volatility. $\alpha+\beta<1$ indicates low volatility, $\alpha+\beta=1$ indicates high volatility, and $\alpha+\beta>1$ indicates extremely high volatility. Table 4 and table 5 show that stock and government bond volatility in ASEAN-5 countries is catagorised as high volatility. These indicate that the stock and government bond volatility in all ASEAN-5 countries will persist with a high volatility magnitude.

Table 5. Government Bond Return Volatility Model Output

\begin{tabular}{ccccc}
\hline Countries & $\omega$ & $\alpha$ & $\beta$ & $\alpha+\beta$ \\
\hline \multirow{2}{*}{ Indonesia } & 0,0000 & 0,1681 & 0,8323 & 1,0004 \\
& $(0,0000)$ & $(0,0064)$ & $(0,0045)$ & \\
Malaysia & 0,0000 & 0,1956 & 0,8246 & 1,0201 \\
& $(0,0000)$ & $(0,0051)$ & $(0,0037)$ & \\
Philippines & 0,0000 & 0,1080 & 0,9024 & 1,0105 \\
& $(0,0000)$ & $(0,0047)$ & $(0,0027)$ & \\
Singapore & 0,0000 & 0,1168 & 0,8607 & 0,9775 \\
& $(0,0000)$ & $(0,0080)$ & $(0,0083)$ & \\
Thailand & 0,0000 & 0,1270 & 0,8545 & 0,9814 \\
& $(0,0000)$ & $(0,0054)$ & $(0,0057)$ & \\
& & & &
\end{tabular}

Notes:

- $\operatorname{GARCH}(1,1)$ model.

- All parameters significant at $1 \%$ level.

- Standard error in paraphrase.

\subsection{Volatility Spillover Analysis of the Stock and Government Bond Return}

This section will discuss the volatility spillover between stock and government bond return using the BEKK-GARCH method. The spillover effect will be indicated in the off-diagonal element. Spillover volatility from the stock 
market to the government bond market will be shown by $\mathrm{a}_{12}$ and $\mathrm{b}_{12}$ estimation parameter and spillover volatility from the government bond market to the government bond market will be shown by $a_{21}$ and $b_{21}$ estimation parameter.

Meanwhile, $2 b_{11} b_{21}$ and $2 b_{12} b_{22}$ parameters will show the effect of changes in the covariance of the two variables on the current volatility magnitude. Furthermore, the results of BEKK-GARCH analysis for each country are presented in the following table:

Table 6. Stock and Government Bond Volatility Spillover

\begin{tabular}{cccccccccccc}
\hline & \multicolumn{1}{c}{ INDONESIA } & \multicolumn{2}{c}{ MALAYSIA } & \multicolumn{1}{c}{ PHILIPPINES } & \multicolumn{3}{c}{ SINGAPORE } & \multicolumn{2}{c}{ THAILAND } \\
\hline \multicolumn{1}{c}{ Variable } & Coeficients & Significancy & Coeficients & Significancy & Coeficients & Significancy & Coeficients & Significancy Coeficients & Significancy \\
\hline mean (stocks) & 0,00077 & 0,00020 & 0,00025 & 0,01910 & 0,00072 & 0,00004 & 0,00033 & 0,01293 & 0,00080 & 0,00001 \\
mean (gov. bond) & 0,00060 & 0,00000 & 0,00022 & 0,00000 & 0,00027 & 0,00000 & 0,00014 & 0,00000 & 0,00023 & 0,00000 \\
& & & & & & & & & & & \\
\\
$\omega_{11}$ & 0,00237 & 0,00000 & 0,00069 & 0,00000 & 0,00337 & 0,00000 & 0,00089 & 0,00000 & 0,00168 & 0,00000 \\
21 & 0,00043 & 0,00000 & $-0,00007$ & 0,06168 & $-0,00026$ & 0,00000 & $-0,00015$ & 0,01598 & $-0,00014$ & 0,00952 \\
22 & 0,00052 & 0,00000 & 0,00018 & 0,00000 & 0,00024 & 0,00000 & 0,00038 & 0,00000 & 0,00037 & 0,00000 \\
$\mathrm{a}_{11}$ & 0,30315 & 0,00000 & 0,24508 & 0,00000 & 0,40623 & 0,00000 & 0,26262 & 0,00000 & 0,31568 & 0,00000 \\
$\mathrm{a}_{12}$ & 0,00410 & 0,42296 & $-0,00145$ & 0,62715 & 0,00117 & 0,79724 & $-0,00689$ & 0,09464 & $-0,02013$ & 0,00000 \\
$\mathrm{a}_{21}$ & 0,28269 & 0,00000 & 0,05330 & 0,57633 & $-0,08951$ & 0,15082 & 0,05819 & 0,30630 & $-0,02347$ & 0,75229 \\
$\mathrm{a}_{22}$ & 0,39936 & 0,00000 & 0,52989 & 0,00000 & 0,30544 & 0,00000 & 0,35023 & 0,00000 & 0,36144 & 0,00000 \\
$\mathrm{~b}_{11}$ & 0,93764 & 0,00000 & 0,96545 & 0,00000 & 0,87684 & 0,00000 & 0,96144 & 0,00000 & 0,94229 & 0,00000 \\
$\mathrm{~b}_{12}$ & $-0,00623$ & 0,00377 & 0,00198 & 0,12485 & 0,01075 & 0,00005 & 0,00208 & 0,12690 & 0,00626 & 0,00000 \\
$\mathrm{~b}_{21}$ & $-0,08086$ & 0,00000 & $-0,01050$ & 0,79256 & 0,00353 & 0,88970 & $-0,01520$ & 0,49818 & 0,04953 & 0,17197 \\
$\mathrm{~b}_{22}$ & 0,92134 & 0,00000 & 0,86979 & 0,00000 & 0,94830 & 0,00000 & 0,92075 & 0,00000 & 0,91488 & 0,00000 \\
\hline
\end{tabular}

From the BEKK-GARCH $(1,1,1)$ estimation results above, we can see that the volatility spillover phenomenon in ASEAN-5 countries is varied. The twoway volatility spillover (bi-directional volatility spillover), both from the stock market to the government bond market and from the government bond market to the stock market only occurred in Indonesia. In the Philippines and Thailand, there was only one-way volatility spillover (unidirectional spillover) from the stock market to the government bond market. Meanwhile, there is no volatility spillover in Malaysia and Singapore.

The occurrence of volatility spillover between the stock market and the government bond market in a country is determined by many factors. Various empirical studies have proved that after the financial crisis, both 1998 and 2008, the level of financial market integration between countries has increased. Referring to a study by the International Monetary Fund through the Global Financial Stability Report [6], the depth of financial markets and the depth of financial institutions, especially in developing countries, have an important role in buffering the turmoil that occurs in other financial markets.

Malaysia and Singapore, both have a depth financial market and financial institution. The depth of the financial market plays an important role in absorbing shocks so that shocks in the stock market do not spill to the bond 
market and shocks in the bond market also did not cause shocks in the stock market.

For countries with not-so-deep financial markets such as Indonesia, shocks in one market will spill over to other markets. Shocks in the stock market will create shocks in the government bond market, conversely shocks in the government bond market will increase the volatility in the stock market. This is in line with Dean et al. [3] hypothesis that the stock market and government bonds market have a financial contagion effect. The financial contagion effect is a condition in which shocks can occur without being triggered by certain information or described as an overreaction to news disclosures. This hypothesis predicts that bad news in one market will be send to other markets, regardless of economic fundamentals. Therefore, spillovers can occur in both directions.

Understanding the volatility spillover and interaction between the stock and bonds can help the authorities to determine the right policies to support financial system stability. Malaysia and Singapore markets have no volatility spillover effect as investors behave as the flight to quality theory. When there is a bad news on the stock market, investor will liquidate their investments thus increase the volatility in stock market. Subsequently, investor will shift their investment to bond market so that volatility in the bond market tend to stabilize, vice versa. Menwhile, the Indonesia stock and government bond market have a positive correlation and move together in the same way. When there is a bad news on the stock market, investor tend to liquidate their investments both in the stock market and bond market thus increase the volatility in both markets. This behavior occurs because of the high share of foreign ownership in the stock and government bond markets in Indonesia. For Indonesian authorities, one of the objectives to deepen the Indonesian financial market is to increase the participation of domestic investor. An increase in domestic investors' participation in the stock and government bond markets is expected to strengthen Indonesia's financial system surveillance especially to face the effects of turmoil in global financial markets. Another thing to do is to provide derivative instruments for hedging purposes. In the event of turmoil in global financial markets or bad market conditions, investors can hedge their investment in Indonesia through derivative instruments instead of divesting their investment in Indonesia.

Beside policymakers, understanding the volatility spillover and interaction between the stock and government bond market has significant managerial implications for investment managers, including allocating investment in financial assets, managing the investment portfolio, and managing market risk of investment portfolios. Previous empirical studies find that financial integration among ASEAN-5 countries is increasing, decreasing the 
long-term diversification benefits in the ASEAN-5 market. The knowledge of the volatility spillover between the stock and government bond market is useful for an investment manager in preparing investment portfolios that include ASEAN-5 countries. The two-way volatility spillover between the stock and government bond market required the investment manager to search for other financial asset in the event of increasing volatility of any assets.

\section{Conclusion}

Based on the results of the analysis and discussion described, the following conclusions can be drawn:

1. The role of foreign investors in the stock market and the bond market of ASEAN-5 is quite dominant in the range of 20-40\%, except Singapore which is included in the category of developed countries. Indonesia is a country with the highest dominance of foreign investors among other ASEAN-5 countries, which is around $40 \%$ both in the stock market and the bond market.

2. Analysis of volatility using univariate GARCH $(1,1)$ showed that the volatility in the stock and bond markets in ASEAN-5 falls into the category of high volatility where if there is a shock the volatility will have a tendency to last for a long time and a relatively large magnitude.

3. The estimation results using BEKK-GARCH show that the phenomenon of spillover volatility in ASEAN-5 countries varies. There is no indication of volatility spillover in Singapore and Malaysia, while in Thailand and Philippines there is an indication of one-way volatility spillover, namely from the stock market to the bond market. Meanwhile, bi-directional spillover, namely from the stock market to the bond market and from the bond market to the stock market occurs in Indonesia.

4. The dominance of foreign investors in a country's financial market does not always have a negative impact as long as it is balanced with the depth of the financial market and the depth of the country's financial institutions. Financial market depth can play a role in absorbing shocks that occur so that shocks in one market do not cause spillover to other markets. 


\section{Recommendation}

1. For Investors, an understanding of the volatility between the returns on the stock market and bonds can be a consideration in making portfolio allocations. Especially in relation to the spillover effect that arises, especially when deciding to invest in developing countries with insufficient levels of financial market depth.

2. For policy makers, understanding the spillover effect between the stock and bond markets can help formulate financial market development policy strategies, especially related to policies to strengthen financial market stability.

3. For further research could include the asymmetrical effect of the multivariate BEKK-GARCH model for modeling conditional covariance. The research can also be expanded by looking at the effects of spillover volatility on other financial assets, especially for Indonesia so that investors and policy makers can learn more about the implications of the research on the decision making process for portfolio allocation or financial market development policies.

\section{References}

[1] Alexander, C.O. (2001). Orthogonal GARCH in Mastering Risk Volume 2 (C.O. Alexander, Ed.). Financial Times-Prentice Hall.

[2] Alkan, B., \& Çiçek, S. (2020). Spillover effect in financial markets in Turkey. Central Bank Review, vol. 20, pp. 53-64.

[3] Dean, W.G., Faff, R.W., \& Loudon, G.F. (2010). Asymmetry in return and volatility spillover between equity and bond markets in Australia. Pacific-Basin Finance Journal, vol. 18, pp. 272-289.

[4] Engle, R.F., Kroner, K.F., (1995). Multivariate simultaneous generalized ARCH. Econometric Theory 11, p.122-150.

[5] Granger, C. (1969). Investigation causal relationships by econometric models: cross spectral methods. Econometrica 424-438.

[6] International Monetary Fund. (2020). Markets in the Time of COVID-19. Global Financial Stability Report. IMF Publications.

[7] Kang, S., Eom, C., Ok, S. (2017). Dynamic volatility spillovers across emerging CDS markets. In: 11th Multidisciplinary Academic Conference, (S. 196-202). Prague.

[8] Kang, S.H., Maitra, D., Dash, S.R., and Brooks, R. (2019). Dynamic spillovers and connectedness between stock, commodities, bonds, and VIX markets. Pacific-Basin Finance Journal, vol. 58. 
[9] Sims, C. (1980). Macroeconomics and reality. Econometrica 48, 1-48.

[10] Sun, T., and Zhang, X. (2009). Spillovers of the U.S. Subprime Financial Turmoil to Mainland China and Hong Kong SAR: Evidence from Stock Markets. Washington, DC. IMF Working Paper 09/166.

[11] Tauchen, G. E. and Pitts, M. (1983) The Price Variability-Volume Relationship on Speculative Markets, Econometrica, 51, 485-506. 